\title{
Determinants and adverse perinatal outcomes of low birth weight newborns delivered in Hawassa University Comprehensive Specialized Hospital, Ethiopia: a cohort study
}

\author{
Melaku Desta ${ }^{1^{*}}$, Mesfin Tadese ${ }^{2}$, Bekalu Kassie ${ }^{1}$ and Mihrete Gedefaw ${ }^{3}$
}

\begin{abstract}
Objective: Globally an estimated 15\% to 20\% of all births are low birth weight, representing more than 20 million births a year. Low birth weights are at a greater risk of both short and long-term sequels. Therefore, this study was conducted to assess determinants and perinatal outcomes of low birth weight newborns delivered in Hawassa University Comprehensive Specialized Hospital, Southern Ethiopia.

Results: A total of 420 mothers were included in the study with a response rate of $97 \%$. The mean birth weights of the neonate were 3360 ( \pm 870 SD) grams and the incidence of low birth weight was found to be $16.6 \%(95 \% \mathrm{Cl}$ 13.46-18.38). Previous abortion $[R R=1.87(2.53,12.5)]$, hypertensive disorder $[R R=4.59(4.93,42.7)]$, having $<4$ antenatal visits $[R R=3.45(2.35,13.8)]$ and prematurity $[R R=18.2(6.24,34.5)]$ was increased the risk of low birth weight. Low birth weight neonates were associated with a low Apgar score $[R R=18.2(6.24,34.5)]$ and early neonatal death $[R R=18.2(6.24,34.5)]$. For this, identifying populations at the greatest risk of previous abortion, hypertensive disorders of pregnancy and prematurity were the major priorities aimed at reducing low birth weight. Incorporate mental health in the prenatal visit, improving the care for a high-risk pregnant woman was also recommended.
\end{abstract}

Keywords: Low birth weight, Determinants, Perinatal outcome, Hawassa, Ethiopia

\section{Introduction}

According to the World Health Organization (WHO), low birth weight is defined as a weight of less than $2500 \mathrm{~g}$ $(5.5 \mathrm{lb})$ at birth. Low birth weight also includes preterm neonates, small for gestational age neonates at term and the combination of these two situations, who particularly have the worst perinatal outcomes [1]. Globally an estimated $15 \%$ to $20 \%$ of all births are low birth weight, representing more than 20 million births a year $[1,2]$.

The mother's own fetal growth and her diet during adolescent and her body composition at conception are commonly associated with low birth weight. Other risk factors for low birth weight includes multiple gestations,

\footnotetext{
*Correspondence: melakd2018@gmail.com

1 Department of Midwifery, College of Medicine and Health Science,

Debre Markos University, P.O. Box 226, Debre Markos, Ethiopia

Full list of author information is available at the end of the article
}

previous abortion, young women, socio-economic status, infections, maternal nutrition and lifestyle, and medical disorders during pregnancy including hypertensive disorders, fetal infection, and anomalies and placental pathologic conditions [2-5].

Low birth weight is related to a range of both short and long-term sequels such as prematurity. Each year, about 1.1 million babies die from complications of prematurity. Low birth weight neonates have a $>20$ times greater risk of dying than neonates with birth weight of $>2500 \mathrm{~g}[6$, 7]. Those who survive tend to remain undernourished, with reduced muscle strength and growth, and have impaired immune function and this high risk of disease. Low birth weight neonates are not only at high risk of death but also are at increased risk of long-term neurologic disability, impaired language development, reduced cognitive abilities and IQ, and increased risk of medical disorders including cardiovascular disease and diabetes 
later in life $[1,8,9]$. Furthermore, due to the immaturity of multiple organs systems, a high risk of respiratory distress, interventricular hemorrhage, sepsis, blindness, and gastrointestinal disorders [10].

Currently, WHO and other organizations are working against reducing low birth weight by $30 \%$ by the year 2025 [1]. Despite those activities, low birth weight is increasing in Ethiopia based on Ethiopian Demographic and Health Survey report; $14 \%$ in 2005, 11\% in 2011, and $13 \%$ in 2016 [11-13]. Concerning the perinatal outcomes, there is a paucity of study across the country. Therefore, this study aimed to assess the determinants and adverse perinatal outcomes of low birth weight newborns delivered in Hawassa University Comprehensive Specialized Hospital (HUCSH).

\section{Main text}

\section{Study setting, design and period}

A hospital-based retrospective cohort study design was conducted in Hawassa University Comprehensive Specialized Hospital (HUCSH) from July 10 to August 15, 2018. The hospital is found at Hawassa City, capital of Southern Nations Nationalities and People's Region (SNNPR), which is $275 \mathrm{~km}$ far from the capital city of the country, Addis Ababa. HUCSH is one of the largest Hospital in the region, which serve as a specialized and teaching hospital at the regional level and provides both delivery and neonatal intensive care unit service. The hospital serves for more than 3 million populations for the region and two zones of Oromia region.

\section{Study population}

All women who delivered in the hospital in the last 1 year were the source populations. There are 4056 women who gave birth in 1 year. Exposed groups were those newborns who had low birth weight (LBW) $(<2500 \mathrm{~g})$ and non exposed or normal birth weight (NBW) was that newborn who weights greater than or equals to $2500 \mathrm{~g}$ and those delivered in the hospital on the same day as enrolled regardless of the mode of delivery and fetal outcome. All women who gave singleton after 28 weeks of gestation or weight of at least $1000 \mathrm{~g}$ were included. However, mothers with congenital anomalies like (hydrocephalus) and multiple pregnancies and incomplete data were excluded. LBW and NBW were selected after reviewing of women's chart, delivery, and neonatal logbook.

\section{Sample size and sampling procedure}

The sample size was determined using double population proportion formula using Open Epi version 3 software, using the following statistical assumptions, $80 \%$ power of the study, 95\% confidence interval, case to control a ratio of 1 to $5(\mathrm{r}=5)$ and considering prematurity and abruption as predictors of low birth weight and prevalence of stillbirth $1 \%$ among non exposed group with an odds ratio of 9 from a cohort study in Zambia [14] and making the final sample size of 434 (73 exposed and 361 unexposed). Exposed groups were selected using random sampling technique. For each exposed, five consecutive nonexposed newborns delivered in the hospital as soon as the exposed diagnosed on the same day in the same as of exposed will be selected as a control group.

\section{Data collection tool and measurement}

Data were collected using structured and pre-tested questionnaire. The questionnaires were adapted from Ethiopian demographic health survey and other related literature [11-13]. Then the adapted questionnaires were modified and conceptualized to fit the research objectives. Admission history, labour follow up sheet, delivery summary and the antenatal care follow-up sheets from the mother's or newborns obstetric records were reviewed to obtain the required information. The principal investigator examined the completeness, consistency, and accuracy of the collected data on regular bases. To assess the perinatal outcomes, the neonates were followed till admitted to the neonatal intensive care unit (NICU) or discharge to home (Additional file 1).

\section{Data processing and analysis}

The data were coded, cleared and entered on Epi data 3.1 software and exported to Statistical package for social science (SPSS) software version 20 for analysis. Summary statistics such as mean and standard deviation and the proportion of the characteristics of LBW and NBW was computed using Chi square. Multivariable logistic regression was carried out to examine the association of the outcome variables with selected determinant factors. Variables that will be associated in bivariate logistic regression with the significance level of $\mathrm{p}$-value $<0.25$ entered into a multivariable logistic regression model to control possible confounding effects. Model was fitted $(\mathrm{p}$-value $=0.39)$ using Hosmer and Lemeshow fit statistic. Variables with a $\mathrm{p}$ value $<0.05$ will be considered as statistically significant factors and odds ratio with $95 \%$ confidence interval was used to measure the strength of association. The analysis was done by reporting guidelines of the Strengthening the Reporting of Observational Studies in Epidemiology (STROBE) statement checklist [15].

\section{Ethical considerations}

Ethical clearance was obtained from Hawassa University, College of Medicine and Health Science, Institutional Review Board Ethical review committee with a Ref. No $I R B / 163 / 10$. Then permission letter was taken from the 
Department of midwifery and Medical clinical director. A brief explanation was given on the objectives as well as the benefit of the study to the concerned officials. Confidentiality and privacy of every patient's information were ensured.

\section{Result}

Socio-demographic and obstetric characteristics

of the respondent

A total of 420 singleton births were included in this analysis with a response rate of $97 \%$. The mean age the participant was $26.9( \pm 5.5 \mathrm{SD})$ years and the birth weight was $3.36 \mathrm{~kg}( \pm 0.87)$. Seventy women had given a low birth weight (LBW) newborn, this constitutes an incidence of $16.6 \%$ (95\% CI 13.46-18.38). Of those women who had LBW, 41 (58.6\%) were in the age group of
20-34 years and above one third (68\%) resides outside Hawassa. Mothers with LBW infants were more likely to be multigravida (61\%), had a complication in the previous pregnancy (48.8\%) and recent pregnancy (65.7\%). Hypertensive disorder of pregnancy (37.1\%) and antepartum hemorrhage (22.9\%) were common among mothers gave birth with LBW newborn. Similarly, 33\% of women with LBW had Antenatal care (ANC) visit; of that $60.4 \%$ had ANC visits $<4$ times. Significant proportions (72.9\%) of LBW were born preterm and nearly two-thirds (64.6\%) of normal birth weight (NBW) newborns were male (Table 1).

\section{Determinants of low birth weight}

In bivariate analysis, 11 variables were significant and fitted for multivariable regression with $\mathrm{p}$-value $<0.25$. Only

Table 1 Sociodemographic and obstetrical characteristics of LBW in HUCSH, 2018

\begin{tabular}{|c|c|c|c|}
\hline Variables & Category & LBW n (\%) & NBW n (\%) \\
\hline \multirow[t]{3}{*}{ Age } & $<20$ & $15(21.4 \%)$ & $15(15.7 \%)$ \\
\hline & $20-34$ & $41(58.6 \%)$ & $243(69.4 \%)$ \\
\hline & $\geq 35$ & $14(20 \%)$ & $52(14.9)$ \\
\hline \multirow[t]{2}{*}{ Residence } & Outside Hawassa & $48(68.6 \%)$ & $221(63.1 \%)$ \\
\hline & Hawassa and around & $22(31.4 \%)$ & $129(36.9 \%)$ \\
\hline \multirow[t]{3}{*}{ Gravidity } & One & $27(38.6 \%)$ & $105(30 \%)$ \\
\hline & $2-4$ & $30(42.9 \%)$ & $149(42.6 \%)$ \\
\hline & $\geq 5$ & $13(18.5 \%)$ & $96(27.4 \%)$ \\
\hline \multirow[t]{2}{*}{ Complication in previous pregnancy } & Yes & $21(48.8 \%)$ & $146(59.6 \%)$ \\
\hline & No & $22(51.2 \%)$ & $99(40.4 \%)$ \\
\hline \multirow[t]{2}{*}{ Previous abortion } & Yes & $9(20.9 \%)$ & $31(12.7 \%)$ \\
\hline & No & $34(79.1 \%)$ & $217(87.3 \%)$ \\
\hline \multirow[t]{2}{*}{ Complication in recent pregnancy } & Yes & $46(65.7 \%)$ & $100(28.6 \%)$ \\
\hline & No & $24(34.3 \%)$ & $250(71.4 \%)$ \\
\hline \multirow[t]{2}{*}{ Hypertensive disorder } & Yes & $26(37.1 \%)$ & $38(50 \%)$ \\
\hline & No & $44(62.9 \%)$ & $38(50 \%)$ \\
\hline \multirow[t]{2}{*}{$\mathrm{APH}$} & Yes & $16(22.9 \%)$ & $28(36.8 \%)$ \\
\hline & No & $54(87.1 \%)$ & $48(63.2 \%)$ \\
\hline \multirow[t]{2}{*}{ Infection } & Yes & $14(20 \%)$ & $13(17.1 \%)$ \\
\hline & No & $56(80 \%)$ & $63(82.9 \%)$ \\
\hline \multirow[t]{2}{*}{ Antenatal anemia } & Yes & $13(18.6 \%)$ & $7(9.2 \%)$ \\
\hline & No & $60(81.4 \%)$ & $76(90.8 \%)$ \\
\hline \multirow[t]{2}{*}{ ANC visit } & Yes & $16(23 \%)$ & $32(9 \%)$ \\
\hline & No & $54(77 \%)$ & $318(91 \%)$ \\
\hline \multirow[t]{2}{*}{ Frequency of ANC visit } & $<4$ visit & $29(60.4 \%)$ & $115(45.8 \%)$ \\
\hline & $\geq 4$ visit & $19(39.6 \%)$ & $136(54.2 \%)$ \\
\hline \multirow[t]{3}{*}{ Gestational age } & $<37$ week & $51(72.9 \%)$ & $32(9.1 \%)$ \\
\hline & $>42$ week & $4(5.7)$ & $69(19.7 \%)$ \\
\hline & 37-42 week & $15(21.4 \%)$ & $249(71.2 \%)$ \\
\hline \multirow{2}{*}{ Sex of the fetus } & Male & $36(51.4 \%)$ & $226(64.6 \%)$ \\
\hline & Female & $34(48.6 \%)$ & $124(35.4 \%)$ \\
\hline
\end{tabular}


4 variables; previous abortion, a hypertensive disorder of pregnancy, the frequency of ANC visit and gestational age at birth remained determinants of LBW (Table 2). Those women who have a history of previous abortion in their lifetime $[R R=1.87(2.53,12.5)]$ had two times the risk of LBW than those who haven't the event. Women who had a hypertensive disorder of pregnancy $[R R=4.59$ $(4.93,42.7)]$ had 4 and half times risk to gave LBW newborn than their counterparts. Similarly, the risk of LBW was higher among women who have $<4$ ANC visits $[R R=3.45(2.35,13.8)]$. Preterm birth was the strongest determinant for $\mathrm{LBW}[\mathrm{RR}=18.2(6.24,34.5)]$, premature newborns were 18 times more likely to be LBW.

\section{Perinatal outcomes of low birth weight}

Above two-thirds (68\%) of the LBW neonates and nearly half (48\%) of the NBW neonates had at least one adverse perinatal outcomes. LBW newborns were at the higher risk of Low Apgar score (42\%), early neonatal death (19.3\%) and NICU admission (22.6\%). LBW neonates were two times more likely at risk of low Apgar score
$[R R=2.29(1.88,5.96)]$ than the NBW group. The risk of early neonatal death was three times $[R R=3.02(1.63$, 6.26)] more likely among the LBW newborns than the NBW neonates (Table 3).

\section{Discussion}

The study aimed to assess the determinants and perinatal outcomes of low birth weight at Hawassa specialized Hospital, Southern Ethiopia. It was found that mothers who have a previous abortion, the frequency of ANC visit; gestational age at birth and hypertensive disorders of pregnancy was statistically significant determinants of low weight at birth. The incidence of LBW in this hospital is $16.6 \%$, which is in line with a country findings of the recent meta-analysis, 17\% [16]. This is higher than the findings of Zambia [14] and Tanzania [17], showed that $10.6 \%$ of LBW. This might be due to a high prevalence of home delivery, preterm delivery, hypertension during pregnancy, antepartum hemorrhage, and study area difference, in our case tertiary hospital, increased the referral of complicated cases, increased risk of LBW.

Table 2 Determinants of Low birth weight in HUCSH, Southern Ethiopia, 2018

\begin{tabular}{|c|c|c|c|c|c|}
\hline Variables & Category & LBW & NBW & CRR $[95 \% \mathrm{Cl}]$ & ARR $[95 \% \mathrm{Cl}]$ \\
\hline \multirow[t]{3}{*}{ Age } & $<20$ & 15 & 15 & $1.01(0.45,2.33)$ & $1.56(0.76,3.84)$ \\
\hline & $20-34$ & 41 & 243 & $0.63(0.32,1.23)$ & $0.85(0.45,2.95)$ \\
\hline & $\geq 35$ & 14 & 52 & 1 & 1 \\
\hline \multirow[t]{3}{*}{ Gravidity } & One & 27 & 105 & $1.89(0.97,4.67)$ & $2.33(0.41,12.3)$ \\
\hline & $2-4$ & 30 & 149 & $1.64(0.81,3.38)$ & $2.01(0.03,2.43)$ \\
\hline & $\geq 5$ & 13 & 96 & 1 & 1 \\
\hline \multirow[t]{2}{*}{ Complication in previous pregnancy } & Yes & 21 & 146 & $0.65(0.34,1.24)$ & $0.87(0.06,12.6)$ \\
\hline & No & 22 & 99 & 1 & 1 \\
\hline \multirow[t]{2}{*}{ Previous abortion } & Yes & 9 & 31 & $1.83(0.83,4.38)$ & $1.87(2.53,12.5)$ \\
\hline & No & 34 & 217 & 1 & 1 \\
\hline \multirow[t]{2}{*}{ Complication in recent pregnancy } & Yes & 46 & 100 & $4.95(2,85,8.61)$ & $3.43(0.65,4.78)$ \\
\hline & No & 24 & 250 & 1 & 1 \\
\hline \multirow[t]{2}{*}{ Hypertensive disorder } & Yes & 26 & 38 & $4.91(2.71,8.89)$ & $4.59(4.93,42.7)$ \\
\hline & No & 44 & 38 & 1 & 1 \\
\hline \multirow[t]{2}{*}{$\mathrm{APH}$} & Yes & 16 & 28 & $3.45(1.75,6.87)$ & $2.39(0.21,25.5)$ \\
\hline & No & 54 & 48 & 1 & 1 \\
\hline \multirow[t]{2}{*}{ Infection } & Yes & 14 & 13 & $6.89(3.03,15.7)$ & $4.00(0.26,60.3)$ \\
\hline & No & 56 & 63 & 1 & 1 \\
\hline \multirow[t]{2}{*}{ Antenatal anemia } & Yes & 13 & 7 & $2.35(0.93,7.13)$ & $0.18(0.01,3.32)$ \\
\hline & No & 60 & 76 & 1 & 1 \\
\hline \multirow{5}{*}{$\begin{array}{l}\text { Frequency of ANC visit } \\
\text { Gestational age }\end{array}$} & $<4$ visit & 29 & 115 & $1.59(0.85,2.98)$ & $3.45(2.35,13.8)$ \\
\hline & $\geq 4$ visit & 19 & 136 & 1 & 1 \\
\hline & $<37$ week & 51 & 32 & $23.5(11.9,46.3)$ & $18.2(6.24,34.5)$ \\
\hline & $>42$ week & 4 & 69 & $0.87(0.28,2.71)$ & $0.57(0.03,14.4)$ \\
\hline & 37-42 week & 15 & 249 & 1 & 1 \\
\hline \multirow[t]{2}{*}{ Sex of the fetus } & Male & 36 & 226 & $0.56(0.33,0.94)$ & $0.45(0.23,2.48)$ \\
\hline & Female & 34 & 124 & 1 & 1 \\
\hline
\end{tabular}


Table 3 Perinatal outcomes of low birth weight in HUCSH, Southern Ethiopia, 2018

\begin{tabular}{|c|c|c|c|c|c|}
\hline \multirow[t]{2}{*}{ Perinatal outcomes } & \multirow[t]{2}{*}{ Category } & \multicolumn{2}{|c|}{ Birth weight (Kg) } & \multirow[t]{2}{*}{ CRR [95\% Cl] } & \multirow[t]{2}{*}{ ARR $[95 \% \mathrm{Cl}]$} \\
\hline & & LBW & NBW & & \\
\hline \multirow[t]{2}{*}{ Perinatal complications } & Yes & $48(68.9 \%)$ & $168(48 \%)$ & $2.65(1.51,4.64)^{*}$ & $2.87(0.34,24.5)$ \\
\hline & No & $22(31.1 \%)$ & $182(52 \%)$ & 1 & 1 \\
\hline \multirow[t]{2}{*}{ Still birth $(n=216)$} & Yes & $17(35.4 \%)$ & $50(30 \%)$ & $1.02(0.58,1.79)$ & \\
\hline & No & $31(64.6 \%)$ & $118(70 \%)$ & 1 & \\
\hline \multirow[t]{2}{*}{ Low Apgar $(n=149)$} & Yes & $13(42 \%)$ & $23(19.5 \%)$ & $3.33(1.93,5.77)^{*}$ & $2.29(1.88,5.96)^{* *}$ \\
\hline & No & $18(58 \%)$ & $95(80.5)$ & 1 & 1 \\
\hline \multirow[t]{2}{*}{ Early neonatal death } & Yes & $6(19.3 \%)$ & $8(6.7 \%)$ & $3.34(1.28,8.66)$ & $3.02(1.63,6.26)^{* *}$ \\
\hline & No & $25(80.7 \%)$ & $108(93.3)$ & 1 & 1 \\
\hline \multirow[t]{2}{*}{ NICU admission } & Yes & $7(22.6 \%)$ & $12(10 \%)$ & $2.34(1.17,4.65)^{*}$ & $2.52(0.19,3.26)$ \\
\hline & No & $24(87.4 \%)$ & 106 (90\%) & 1 & 1 \\
\hline
\end{tabular}

Kg implies weight in kilogram

* showed variables fitted for mutivariable logistic regresion

** shows significant at $\mathrm{p}$-value $<0.05$

The study revealed that those mothers who have at least one previous abortion were two times more likely to deliver LBW neonates compared to those who have no abortion history. This is similar to studies conducted in Denmark and the US [18, 19], and a meta-analysis was done in Canada [20]. The study also supported by Bossley [21] found that women who had an abortion in the first or second trimester had a $35 \%$ increased risk of a LBW baby and a $36 \%$ raised risk of a pre-term baby in later pregnancies and Tsegaye et al. [22] revealed that previous adverse pregnancy outcomes were associated with the recent outcome. The possible explanation for this might be most likely to be physical damage to the cervix caused methods of abortion, reduce the tensile strength of the cervical plug, result in the preterm birth subsequently LBW and due to psychological stress for the previous occurrence of the event. Hence stress-depression is associated with previous abortion [23] and other pregnancy complications [24] and lowers dietary diversity of women $[25,26]$, reduces fetal nutrients vital for development leads to an increased risk of LBW [27-30]. Conversely, various kinds of literature suggested that induced abortion does not increase the risk for low birth weight in the subsequent pregnancy [31-33]. This might be explained by the differences in the methods used to perform abortion at different times and different countries.

This study found that one of the major causes of adverse pregnancy outcomes, the hypertensive disorder of pregnancy has a significant impact on pregnant women to have LBW neonate. There was greater risk of delivering a low weight infant among mothers with hypertension during pregnancy as compared to those who did not develop the disease. The effect is more pronounced if delivery occurs before reaching term [34]. Similar studies shown comparable results $[17,35-40]$, suggested that the significant association of hypertension disorder and LBW. This explained by the fact that hypertension cause uteroplacental insufficiency. Similarly, the study revealed that mothers who had less than four ANC visit were more at risk to deliver a low weight neonate compared to mothers who attended more than four times. This is comparable to similar studies [35, 41-44]. This is also supported with studies done by Gizaw et al. [28], Mahmud et al. [41], Oulay et al. [45] and Kamala et al. [46] revealed that ANC visit $<4$ times were associated with LBW.

In addition to this, premature birth was another most significant determinant of LBW. Those women who deliver before 37 completed weeks are more at risk to give low weight births than those giving birth at term. This is in accordance with different studies [35, 36, 42, 47-51] and a meta-analysis did in Ethiopia [16] stated that delivery remote from term associated with LBW. When the neonates delivered before reaching term, they are likely to be small and the babies are more likely to have decreased skeletal muscle mass and subcutaneous fat tissue [52].

Likewise, the study found that LBW newborns are associated with an increased risk of a low Apgar score and early neonatal death. The finding is in line with a study in Brazil [50] and Tanzania [17] have found that LBW infants had a higher risk of having Apgar scores below 7 at the 5th min and Yasmin in Bangladesh [53] had ascertained the role of LBW on the increased risk of early neonatal death. Similarly, the finding is in accordance with studies done by Bayou [40], Sangamam [54], Chibwesha [14] and Mitao [17] demonstrated that early 
neonatal mortality rate was higher among LBW babies. These facts indicate that low weight at birth increases the risk of intrauterine growth restriction and early neonatal death. It also explained due to the high burden of preterm birth (73\%) and its complications, which is expected to have a higher risk for mortality. Hence, several organ systems of human fetus usually immature before the end of 37 weeks of gestational age leads to difficult to maintain the extra uterine environment, particularly from pulmonary hypoplasia, end up with mortality.

\section{Conclusion}

Low birth weight neonates are still at increased risk of adverse perinatal outcomes in the study area. Identifying populations at greatest risk of previous abortion and incorporate mental health in the prenatal visit, hypertensive disorders of pregnancy and prematurity were the major priorities and fundamental strategies for the success of programmers and policies aimed at reducing low birth neonates. The early screening of high-risk pregnancy and the care provided for low birth weight newborn should be improved and further prospective study such as on the type of LBW (very LBW and Extremely very $L B W$ ) on perinatal outcomes should be addressed.

\section{Limitations}

Despite it was a cohort study and extensive efforts have been made, the finding could be interpreted in the presence of some inevitable limitations. The study might underestimate early neonatal death due unable to assess outcome after NICU admission and death after discharge and its retrospective nature might prevent some variables, as educational level, Iron-folic acid supplementation, maternal mental health and dietary pattern of women.

\section{Additional file}

Additional file 1. English version Questionnaire of determinants and outcomes of low birth weight in HUCSH, Southern Ethiopia, 2018.

\begin{abstract}
Abbreviations
ANC: Ante Natal Care; ARR: adjusted relative risk; HUCSH: Hawassa University Comprehensive Specialized Hospital; LBW: low birth weight; NBW: normal birth weight; NICU: neonatal intensive care unit; SNNPR: Southern Nations Nationalities and People's Region; STROBE: Strengthening the Reporting of Observational Studies in Epidemiology; WHO: World Health Organization.
\end{abstract}

\section{Authors' contributions}

MD conceived and designed the study, supervised the data collection, analyzed the data and wrote up the manuscript. MT assisted in designing study, reviewed and analyzed the study and wrote up the manuscript. BK and MG participated in analyzed of the data and wrote up of the manuscript. All authors read and approved the final manuscript.

\section{Author details}

${ }^{1}$ Department of Midwifery, College of Medicine and Health Science, Debre Markos University, P.O. Box 226, Debre Markos, Ethiopia. ${ }^{2}$ Department of Midwifery, College of Medicine and Health Science, Debre Berhan University, Debre Berhan, Amhara Region, Ethiopia. ${ }^{3}$ Department of Nursing, College of Medicine and Health Science, Debre Markos University, Debre Markos, Ethiopia.

\section{Acknowledgements}

Authors are thankful for Hawassa University and hospital health workers.

\section{Competing interests}

The authors declare that they have no competing interests.

\section{Availability of data and materials}

All the datasets used and analyzed during the current study are available from the manuscript. For this, no need of requesting of the author.

\section{Consent to publication}

Not applicable.

\section{Ethics approval and consent to participate}

The study protocol was reviewed and approved by Hawassa University, College of Medicine and Health Science Institutional Review board review committee with a Ref. No IRB/163/10. Official letter of cooperation was obtained from College of Medicine and Health Science to Hawassa specialized Hospital and permission was secured from medical director. All study participant's charts were reviewed and returned back as soon as the completion of data extraction. Information obtained in the study was stored confidential and secured.

Funding

No funding sources.

\section{Publisher's Note}

Springer Nature remains neutral with regard to jurisdictional claims in published maps and institutional affiliations.

Received: 18 December 2018 Accepted: 22 February 2019

Published online: 04 March 2019

\section{References}

1. Organization WH. Global nutrition targets 2025: Low birth weight policy brief. Geneva: World Health Organisation; 2014.

2. Wardlaw TM. Low birthweight: country, regional and global estimates. New York: UNICEF; 2004.

3. Organization WH. Towards the development of a strategy for promoting optimal fetal growth. Geneva: World Health Organization; 2004.

4. Villar J, Papageorghiou AT, Knight HE, Gravett MG, lams J, Waller SA, et al. The preterm birth syndrome: a prototype phenotypic classification. Am J Obstet Gynecol. 2012;206(2):119-23.

5. Shah PS, Zao J, Births KSGoDoPL. Induced termination of pregnancy and low birthweight and preterm birth: a systematic review and meta-analyses. BJOG Int J Obstet Gynaecol. 2009;116(11):1425-42.

6. Kramer MS. Determinants of low birth weight: methodological assessment and meta-analysis. Bull World Health Organ. 1987;65(5):663.

7. Badshah S, Mason L, McKelvie K, Payne R, Lisboa PJ. Risk factors for low birthweight in the public-hospitals at Peshawar, NWFP-Pakistan. BMC Public Health. 2008;8(1):197.

8. Zerbeto AB, Cortelo FM, Élio Filho B. Association between gestational age and birth weight on the language development of Brazilian children: a systematic review. Jornal de Pediatria (Versão em Português). 2015;91(4):326-32.

9. UNICEF. Undernourishment in the womb can lead to diminished potential and predispose infants to early death. New York: UNICEF; 2016.

10. You D, Hug L, Ejdemyr S, Idele P, Hogan D, Mathers C, et al. Global, regional, and national levels and trends in under-5 mortality between 1990 and 2015, with scenario-based projections to 2030: a systematic 
analysis by the UN Inter-agency Group for Child Mortality Estimation. Lancet. 2015;386(10010):2275-86.

11. bālaśelțān EYs, Macro O. Ethiopia demographic and health survey, 2005. Addis Ababa: Central Statistical Authority; 2006.

12. Macro: CSAaO. Ethiopia demographic and health survey 2011. Addis Ababa: Central Statistical Agency and ORC Macro; 2011.

13. Macro: CSAaO. Ethiopia demographic and health survey 2016. Addis Ababa: Central Statistical Agency and ORC Macro; 2016.

14. Chibwesha CJ, Zanolini A, Smid M, Vwalika B, Phiri Kasaro M, Mwanahamuntu $\mathrm{M}$, et al. Predictors and outcomes of low birth weight in Lusaka, Zambia. Int J Gynecol Obstet. 2016;134(3):309-14.

15. Von Elm E, et al. The strengthening the reporting of observational studies in epidemiology (STROBE) statement: guidelines for reporting observational studies. Bull World Health Organ. 2007;85:867-72.

16. Endalamaw A, Engeda EH, Ekubagewargies DT, Belay GM, Tefera MA. Low birth weight and its associated factors in Ethiopia: a systematic review and meta-analysis. Italian J Pediatr. 2018;44:141.

17. Mitao M, Philemon R, Obure J, Mmbaga BT, Msuya MS, Mahande MJ. Risk factors and adverse perinatal outcome associated with low birth weight in Northern Tanzania: a registry-based retrospective cohort study. Asian Pac J Reprod. 2016;5(1):75-9.

18. Zhou W, Sørensen HT, Olsen J. Induced abortion and low birthweight in the following pregnancy. Int J Epidemiol. 2000;29(1):100-6.

19. Brown J, Adera T, Masho S. Previous abortion and the risk of low birth weight and preterm births. J Epidemiol Community Health. 2008;62(1):16-22.

20. Shah P, Zao J, on behalf of Knowledge Synthesis Group of Determinants of preterm/LBW births. Induced termination of pregnancy and low birthweight and preterm birth: a systematic review and meta-analyses. BJOG. 2009; 116:1425-42.

21. Boseley S. Abortions may pose risk to future babies, according to study. The Guardian. 2009.

22. Tsegaye B. Kassa A. Prevalence of adverse birth outcome and associated factors among women who delivered in hawassa town governmental health institution, south Ethiopia Reprod Health. 2017:15:193.

23. Abajobir AA, Alati R, Kisely S, Najman JM. Are past adverse pregnancy outcomes associated with maternal anxiety and depressive symptoms in a sample of currently pregnant women? Ethiopian J Health Sci. 2017;27(4):351-62.

24. Zegeye A, Alebel A, Gebrie A, Tesfaye B, Belay YA, Adane F, et al. Prevalence and determinants of antenatal depression among pregnant women in Ethiopia: a systematic review and meta-analysis. BMC Pregnancy Childbirth. 2018;18:462.

25. Poorrezaeian M, Siassi F, Qorbani M, Karimi J, Koohdani F, Asayesh $\mathrm{H}$, et al. Association of dietary diversity score with anxiety in women. Psychiatry Res. 2015:230(2):622-7.

26. Poorrezaeian M, Siassi F, Milajerdi A, Qorbani M, Karimi J, Sohrabi-Kabi $\mathrm{R}$, et al. Depression is related to dietary diversity score in women: a cross-sectional study from a developing country. Ann Gen Psychiatry. 2017;16:39

27. Stylianou-Riga P, Kouis P, Kinni P, Rigas A, Papadouri T, Yiallouros PK, et al. Maternal socioeconomic factors and the risk of premature birth and low birth weight in Cyprus: a case-control study. Reprod Health. 2018;15(1):157.

28. Gizaw B, Gebremedhin S. Factors associated with low birthweight in North Shewa zone, Central Ethiopia: case-control study. Italian J Pediatr. 2018:44(1):76.

29. Van Ngo T, Gammeltoft T, Nguyen HTT, Meyrowitsch DW, Rasch V. Antenatal depressive symptoms and adverse birth outcomes in Hanoi, Vietnam. PLoS ONE. 2018;13(11):e0206650.

30. Liou S-R, Wang P, Cheng C-Y. Effects of prenatal maternal mental distress on birth outcomes. Women Birth. 2016;29(4):376-80.

31. Ke L, Lin W, Liu Y, Ou W, Lin Z. Association of induced abortion with preterm birth risk in first-time mothers. Sci Rep. 2018:8(1):5353.
32. Hogue CJ. Low birth weight subsequent to induced abortion: a historical prospective study of 948 women in Skopje, Yugoslavia. Am J Obstet Gynecol. 1975;123(7):675-81.

33. Bracken MB, Hellenbrand KG, Holford TR, Bryce-buchanan C. Low birth weight in pregnancies following induced abortion: no evidence for an association. Am J Epidemiol. 1986;123(4):604-13.

34. Xiong X, Demianczuk NN, Saunders LD, Wang F-L, Fraser WD. Impact of preeclampsia and gestational hypertension on birth weight by gestational age. Am J Epidemiol. 2002:155(3):203-9.

35. Asmare G, Berhan N, Berhanu M, Alebel A. Determinants of low birth weight among neonates born in Amhara Regional State Referral Hospitals of Ethiopia: unmatched case control study. BMC Res Notes. 2018;11(1):447.

36. Capt TRRG, Maj AD, Sood S, Col AGL, Col BRL. Low birth weight babies: incidence and risk factors. Med J Armed Forces India. 1998;54(3):191-5.

37. Odell CD, Kotelchuck M, Chetty V, Fowler J, Stubblefield PG, Orejuela M, et al. Maternal hypertension as a risk factor for low birth weight infants: comparison of Haitian and African-American women. Matern Child Health J. 2006;10(1):39-46.

38. Lapidus AM. Effects of preeclampsia on the mother, fetus and child. Fetal Monitoring, Pregnancy Birth [online]; 2011.

39. Singh AC, Rana SS. Fetal outcome in hypertensive disorders of pregnancy. Med J Shree Birendra Hosp. 2013;12(1):8-10.

40. Bayou G, Berhan Y. Perinatal mortality and associated risk factors: a case control study. Ethiopian J Health Sci. 2012;22:3.

41. Mahumud RA, Sultana M, Sarker AR. Distribution and determinants of low birth weight in developing countries. J Prev Med Public Health. 2017;50(1):18.

42. Nobile CG, Raffaele G, Altomare C, Pavia M. Influence of maternal and social factors as predictors of low birth weight in Italy. BMC Public Health. 2007:7(1):192.

43. Kader M, Perera NKP. Socio-economic and nutritional determinants of low birth weight in India. North Am J Med Sci. 2014;6(7):302.

44. Khatun S, Rahman M. Socio-economic determinants of low birth weight in Bangladesh: a multivariate approach. Bangladesh Med Res Counc Bull. 2008;34(3):81-6.

45. Oulay L, Laohasiriwong W, Phajan T, Assana S, Suwannaphant K. Effect of antenatal care on low birth weight prevention in Lao PDR: a case control study. F1000Research. 2018;7:1138.

46. Kamala BA, Mgaya AH, Ngarina MM, Kidanto HL. Predictors of low birth weight and 24-hour perinatal outcomes at Muhimbili National Hospital in Dar es Salaam, Tanzania: a five-year retrospective analysis of obstetric records. Pan Afr Med J. 2018;29(1):1-13.

47. Hirve SS, Ganatra BR. Determinants of low birth weight: a community based prospective cohort study. Indian Pediatr. 1994;31(10):1221-5.

48. Osuorah C, Ifediora C, Asinobi I, Ekwochi U, Agwu S, Ndu I, et al. Determinants of survival in low birth weight infants at a tertiary healthcare facility in the South Eastern Nigeria. J Exper Res. 2017;5:1.

49. Noor N, Kural M, Joshi T, Pandit D, Patil A. Study of maternal determinants influencing birth weight of newborn. Arch Med Health Sci. 2015;3(2):239.

50. Coutinho PR, Cecatti JG, Surita FG, Costa ML, Morais SS. Perinatal outcomes associated with low birth weight in a historical cohort. Reprod Health. 2011:8(1):18.

51. Gebremedhin M, Ambaw F, Admassu E, Berhane H. Maternal associated factors of low birth weight: a hospital based cross-sectional mixed study in Tigray, Northern Ethiopia. BMC Pregnancy Childbirth. 2015;15(1):222.

52. Barton L, Hodgman JE, Pavlova Z. Causes of death in the extremely low birth weight infant. Pediatrics. 1999:103(2):446-51.

53. Gaiva MAM, Fujimori E, Sato APS. Neonatal mortality in infants with low birth weigh. Revista da Escola de Enfermagem da USP. 2014;48(5):778-86.

54. Sangamam R. Perinatal mortality and morbidity among low birth weight babies. Int J Community Med Public Health. 2017:2(1):51-8. 